\title{
Narrador, trapero, condensador de restos. Sobre la poética de Marcelo Cohen
}

\author{
Silvina Sánchez ${ }^{\bullet}$ \\ Universidad Nacional de La Plata - \\ CONICET
}

\begin{abstract}
Resumen
El artículo indaga la construcción de imágenes de artista y escritor así como también las concepciones de la creación, del arte y de la literatura que pueden observarse en cierta zona de la obra de Marcelo Cohen. Se consideran tanto su producción crítica-ensayística, fundamentalmente el libro ¡Realmente fantástico! y otros ensayos, como su producción ficcional, en particular la nouvelle "Un hombre amable» (Hombres amables) y el cuento "Usos de las generaciones» (Los acuáticos); con la finalidad de explorar los múltiples cruces, continuidades y rupturas que pueden observarse entre ambas modalidades de escritura y las formas en que, a través de este diálogo prolífico, se trama la construcción de su poética. Se estudian principalmente la imagen de un artista que crea a partir del desperdicio, vinculada con las figuras del trapero y del niño tal como han sido pensadas por Walter Benjamin, y la imagen de un narrador que se obstina en poner en palabras su experiencia. Además, se analizan ciertas figuraciones de la literatura como creación de algo autosuficiente que se incorpora al mundo y como construcción de un lugar, susceptible de despuntar la sensación verdadera y de convocar a los sujetos en reunión, espacio de comunidad hospitalario y amable.

\section{Palabras clave:}

- Narrativa argentina contemporánea · ensayo - Marcelo Cohen . imagen de artista/escritor · figuraciones de la literatura
\end{abstract}

- Profesora en Letras por la Universidad Nacional de La Plata, becaria del CONICET y doctoranda en la Carrera de Doctorado en Letras (FaHCE-UNLP). Ha participado en Jornadas y Congresos y publicado trabajos dedicados especialmente a la literatura argentina contemporánea y a la teoría literaria; entre ellos el libro Cuadernos de Teoría, realizado bajo la dirección de la Dra. Miriam Chiani (2014). 


\begin{abstract}
This article researches the construction of artist's and writer's images, as well as the conceptions of creation, art, and literature that can be observed in certain areas of Marcelo Cohen's works. His critical/essay productions are considered, mainly the book ;Realmente fantástico! y otros ensayos, as well as his fictional output, especially the novella «Un hombre amable» (Hombres amables) and the short story "Uso de las generaciones» (Los acuáticos). The purpose is to explore the multiple overlaps, continuities and rifts that can be observed between both writing approaches and the ways in which, through this prolific dialogue, the construction of his poetics is devised. The image of the artist who creates from waste, linked to the figure of the junkman and the child as thought up by Walter Benjamin, and the image of a narrator whose stubbornness drives him to put his experience in words, are the main objects of the research. Furthermore, the article analyzes certain imaginations of literature such as the creation of something self sufficient that joins the world and as a construction of a place, susceptible to making a real sensation appear and of gathering subjects in reunion, kind and welcoming community space.
\end{abstract}

\title{
Key words:
}

Contemporary Argentinean literature · essay · Marcelo Cohen . artist/writer image $\cdot$ imaginations of literature

Escribir, tarde o temprano, es preguntarse en qué ha consistido, consiste y podría consistir en el futuro la esencia de la literatura

(Cohen, 2006a:8).

La pregunta por la literatura —en qué ha consistido, consiste y podría consistir en el futuro la esencia de la literatura- se reactualiza en cada trazo de escritura que deja delinear la poética de Marcelo Cohen. Las respuestas, siempre tentativas y provisorias, se esgrimen tanto en sus ensayos y textos críticos como en su producción ficcional y asumen la forma de múltiples refracciones. Aquello que aparece formulado en un ensayo se replica en la voz de un personaje de ficción; lo que se dice a modo de reseńa respecto a un libro, una pieza musical, una instalación artística se convierte en estrategia de composición de una novela; la escena de creación que se narra en un cuento se transforma en reflexión de un artículo crítico; la figura de artista que asume un personaje se repite en otro personaje, en algún escritor admirado del que se dice algo, en la imagen de escritor que Cohen construye para sí o en lo que hace con su propia escritura. 
Cada réplica de este juego de espejos es similar y distinta a aquello que refracta, algo la vincula inevitablemente a sus otras apariciones, pero también en algo ejerce un leve deslizamiento: acota, amplía, completa o modifica el esbozo anterior, agrega nuevas aristas, convierte una afirmación en pregunta, un enunciado en imagen, un postulado en procedimiento creativo. En esta forma de diálogo, repartido en cientos de espejos que, además de repetir, transforman y que, a la vez que parecen confirmar, provocan vacilación, se trama la construcción de la poética de Marcelo Cohen. El presente artículo se propone estudiar algunos de los modos que asume la configuración de esta poética. Pretende analizar las concepciones del arte y de la literatura y las imágenes del artista/escritor que se construyen a partir de las relaciones establecidas entre los ensayos, sobre todo los pertenecientes al libro ¡Realmente fantástico! y otros ensayos (2003), la nouvelle "Un hombre amable», publicada en Hombres amables (1998), y el cuento "Usos de las generaciones», incluido en Los acuáticos (2001).

\section{La zona canta}

Dainez, el protagonista de «Un hombre amable», muestra especial atención hacia dos personajes de su barrio, a quienes les dedica ciertos gestos de cuidado y protección. Por un lado, está particularmente interesado por la historia de amor de Roxana y por el devenir de su embarazo. Roxana cuenta que, en las cubetas de la heladería donde trabajaba, fue encontrando las partes fraccionadas de un cuerpo humano y que, al dar con cada una de ellas, las iba llevando a la habitación donde vivía y guardando en su ropero. Hasta que un día, luego de un ruido sísmico, salió del armario "un tipo grandote, muy varonil» (2004:168), quien, como don de agradecimiento por haber recogido amorosamente sus partes, le ofrendó el hijo que crece en su interior. ${ }^{1}$ Los vecinos sospechan de las palabras de Roxana, les resultan improbables, ajenas a toda comprensión racional. Sin embargo, según expresa Cohen en un ensayo sobre las novelas de Peter Handke, el relato es como el canto: «comprenderlo no requiere tanto capacidad analítica como atención abierta" (2003:83). Quizás por eso cuando Dainez logra escuchar el relato de Roxana queda «estupefacto», «atontando por ese cuento» (2004: 185), no duda en creerle y admirar: "ésa era su viveza, habérselas ingeniado bien chunqui para hacer sus ganas, con historia que contar y todo» (2004:185).

El otro personaje amparado por Dainez es Justín, quien, además de músico, es un artista del desecho. En el campito donde estaba el cementerio, entre carrocerías quemadas y neumáticos fofos, ha construido su casa utilizando para ello una camioneta Volkswagen roja y otro montón de materiales como «tablas de aglomerado, cartón, cigüeñales, cojinetes, latas o pies de lámpara de metacrilato» (2004:165). Justín nunca se da por satisfecho, está permanentemente ocupado en la ampliación de sus dominios, de modo tal que es percibido por sus vecinos como «la persona más atareada del barrio» (2004:151). A la camioneta roja le agrega 
un cascajo de Peugeot, unido a través de un conducto de seis metros armado con plástico de botellas, láminas de policarbonato y tela de avión, y, además, alrededor, construye un jardín que, en lugar de flores, tiene enormes bolas de lana de acero sujetas al suelo con cordón y estacas (2004:196). Luego, añade a su composición un ambiente más, un porche de lona y listones, en cuyo centro instala un antiguo sillón de peluquero, sitio donde descansar y contemplar el horizonte de maleza entre la fila de coches quemados.

Según la descripción realizada por Baudelaire y recuperada por Walter Benjamin, el trapero es aquel que registra y recoge todo lo que la gran ciudad arrojó y ha despreciado, «aparta las cosas, lleva a cabo una selección acertada» y «se porta como un tacańo con su tesoro» (1993: 98). ${ }^{2}$ Además, Benjamin también reconoce en los niños una relación empática con los productos residuales. En Calle de mano única expresa que los niños «se sienten irresistiblemente atraídos por los desechos provenientes de la construcción, jardinería, labores domésticas y de costura o carpintería» (2002:18), por esto tienden a frecuentar cualquier sitio buscando, cual cazadores de restos, los sobrantes arrojados por estas labores. Aquí, Benjamin agrega, a esta actividad de recolección que ya se hacía presente en la figura del trapero, una práctica fundamentalmente creativa, similar a la del poeta que edifica su obra con los desperdicios de la gran ciudad. Los niños utilizan los desechos "para relacionar entre sí, de manera nueva y caprichosa, materiales de muy diverso tipo", de modo tal que, en lugar de reproducir las obras de los adultos, «se construyen así su propio mundo objetal, un mundo pequeño dentro del grande» (18).

Justín, cual trapero, busca en la basura con que tropieza y recoge los desperdicios que la sociedad ha arrojado, parte residual de sus actividades o productos que se tiran a fin de ser reemplazados por otros, últimos modelos de un consumo constantemente interpelado por la innovación. Por otra parte, Justín posee «la capacidad de renovar la existencia» con que Benjamin (2011:116) caracteriza a los niños cuando les atribuye una mirada apta para transformar los objetos asignándoles funciones otras, insospechadas. Dice Benjamin que los cajones de los niños son "arsenal y zoológico, museo del crimen y cripta», «un edificio lleno de espinosas castańas que son manguales, de papeles de estaño que son tesoros de plata, de cubos de madera que son ataúdes, de cactáceas que son árboles totémicos y céntimos de cobre que son escudos» (2002:44). Justín sustrae a los objetos de la lógica del intercambio mercantil y del uso para el cual fueron consignados, y descubre en ellos nuevos rostros y posibilidades, de modo tal que un auto descascarado puede ser una vivienda, las bolas de viruta metálica, un jardín de flores.

Pero además, Justín comparte con los niños la capacidad de operar sobre los objetos ejerciendo diversas actividades para renovarlos. Dice Benjamin: «el hecho de coleccionar solo es uno de los procedimientos que le sirven para renovar los objetos; también se los puede pintar, recortar, despegar y, continuando así, toda la escala de las formas en que los niños adquieren los objetos» (2011:116). También Justín recorta, desmonta, adosa, conecta, mueve de un lugar a otro, hace de sus dominios un laboratorio para investigar los usos insospechados del desperdicio. Transforma montones de objetos caducos, dotándolos de nuevas formas, asignándoles otras funciones, estableciendo entre ellos relaciones insólitas. Quizás por esto es definido como «un atractor extraño. Un condensador de restos» (2004:275), aquel capaz de, con mirada de niño y en su obstinada ocupación lúdica, acumular basura, trastos rotos y viejos, y hacer de ellos su vivienda, su jardín, su pequeño mundo objetal. 
Dainez es cuidadoso con Roxana y defiende a Justín, también sigue interesado los derroteros de ambos personajes: la narración, que es historia de amor y de procreación, en Roxana; los avances empeñados de la construcción, arte hecho del desperdicio, en Justín. Pero además, estas dos figuras se reúnen en la configuración del protagonista de la nouvelle: narrador y trapero, Dainez es la síntesis donde confluyen ambos modos de intervención. En el citado ensayo sobre Peter Handke, Cohen propone: «Nada iguala a dos hombres cualesquiera tanto como el hecho de que los dos siempre van a tener una historia que contar» (2003:84). Esta disposición narrativa enlaza a Dainez y a Roxana, y además lo emparenta con otros personajes del barrio, como su hija Sabina que "acumulaba chismes con tanta exuberancia» (166), o Pulpita y sus amigas cuando se juntan en el café Salcedo a intercambiar las historias de sus jefes. Sin embargo, un componente diferencial distingue al protagonista de los otros narradores, mínimos, ocasionales. El relato de Dainez aspira a la totalidad, quiere cantar la zona que los incluye a todos. Por un lado, Dainez relata lo que va sucediendo día a día en su grabador y esta es una primera manera de contar su barrio. Luego, una vez convertido en figura de exaltación y referencia, esas grabaciones son reproducidas por la cofradía que le rinde homenaje y reconstruye su «trayectoria». Además, su relato es replicado por la narración principal, a cargo de un narrador en tercera persona que por momentos mima la voz de su protagonista.

Pero, sobre todo, Dainez es quien, asumiendo también la figura de trapero-niño que describimos en relación a Justín, crea la zona, utilizando para ello las ruinas de un barrio periférico, relegado de las decisiones opulentas y la circulación de mensajes de la gran ciudad. Tal como su amigo, Dainez construye, no solo haciendo del desperdicio su materia principal, sino también emplazado sobre los escombros, subido a la cima de una montańa de basura. De tanto en tanto, Dainez escala el zigurat, se sienta en su taburete giratorio y, al ritmo del movimiento de su mano que se desplaza de derecha a izquierda, hace aparecer lo que se va distinguiendo como las diferentes partes de un barrio. Miriam Chiani postula que «Un hombre amable» es «el relato en el que Cohen narra un acto de poiesis, a partir de requechos» (2010:9). Chiani destaca que la imagen del artista héroe que allí se configura es similar a la del trapero baudelairiano, pero su operación básica ya no es fijar y transfigurar sino narrar (2001a:29). De este modo, Dainez, trapero y también narrador, bajo el impulso de un acto fantástico, crea, donde solo quedaban las ruinas de un barrio postergado, una zona que reúne a Justín, Roxana, Sabina, Pulpita y los demás personajes de la nouvelle. Sitio de comunidad, susceptible de alojar el valor amable.

\section{Un universo de vivencias}

Las réplicas de estas dos figuras, narrador y trapero, se extienden hacia otras zonas de la literatura de Marcelo Cohen. Podemos encontrarlas, también en forma de confluencia, en Helena Saort, personaje de "Usos de las generaciones», quien ha construido un singular objeto artístico denominado «el módulo». El cuento, donde un joven periodista lee la entrevista que le ha realizado a la creadora del «módulo», alterna esta escena de lectura con la transcripción de la entrevista, diferenciada con marcas tipográficas que la tornan reconocible y 
delimitable. Por lo tanto asistimos a dos escrituras que rotan su aparición: la narración principal y el texto periodístico. Pero además, al interior de la entrevista podemos observar la tensión entre narración e información como dos modos diversos de organización del mundo.

El periodista intenta durante todo su encuentro con Helena Saort ubicar su entrevista en el terreno de las «declaraciones» y dotarla de la novedad e inmediatez que toda información requiere. Por ejemplo, con esta finalidad, interpela a la artista sobre la venta y propiedad de la obra convertida en mercancía: «¿Piensa en los derechos de comercialización que hay en juego?» (2001:221). Pero la protagonista se niega una y otra vez a participar de este tipo de intercambio, anticipa de entrada: "las declaraciones me asfixian» y aclara que lo que a ella le interesa es «contar quien soy, cómo hice lo que hice» (219). Para realizar esto elige la forma del relato, hilvana poderosamente una y otra historia, hace pública su subjetividad, construida con los restos de escenas familiares: las visitas con su padre a la exposición de la industria, el tiempo en que su tía Herminia fue a vivir con ella, los paseos con su madre por las tiendas Gehran. De este modo, la artista propone, y opone al discurso informativo, un discurrir "largo y tendido", "tumultoso», "muy de corregirse, muy variopinto" (2001:220), capaz de albergar vaguedades o contradicciones, todas cosas que alteran al periodista siempre en reclamo de brevedad, claridad y definiciones concisas. «Le encarezco que resuma» (228), "¿No tiene otro tipo de ejemplos?» (2011:229) exige el joven, ante lo que Helena le objeta: «Usted querría que yo le explicase todo con pelos y señales... Pero no es así, no» (2001:231). Porque sus narraciones, cercanas a lo extraordinario y a lo fantástico, parecen compartir lo expresado por Benjamin cuando postula que al narrar es fundamental mantener la historia ajena a toda explicación (1986:194). Así, la protagonista, al momento de contar quien es, asume para desplegar su vida los artilugios del arte de narrar.

Cuando Helena relata los orígenes de la creación del «módulo», recupera una noche en que se vio especialmente interpelada por el paso del camión de la basura: «esa noche, en un paroxismo de estremecimientos, me vi elevada a un tipo de alegría que no debería llamar éxtasis, no» (2001:227). Inspirada por la «seducción tan particular» que le provocan «elaboradísimas sustancias sintéticas y organismos naturales complejos, cáscara, hueso, poso de vino, tisanas, vidrio, hoja de col, riñón, costilla, miel, molusco, miga, pulpa de ananá y hasta tejido de encías» (ídem), toda esa materia congregada a diario en las bolsas de residuos domésticos; decide idear el modulo para saciar el deseo generado a partir de su encuentro con los desechos de la vida urbana. Cual trapero, selecciona, recoge y aprecia «todo lo que la gente de nuestra ciudad pelaba, manipulaba, abría, cortaba, hurgaba, trituraba, paladeaba, deglutía, todo lo que desechaba» (227). Pero, además, su imagen de artista se trasviste de niña, dice Helena: «El módulo es un juego. Mire a los niños. De una piedra hacen a un ser humano, de dos palitos una casa. Yo he intentado hacer al revés, pero lo mismo» (2001:240). Con goce infantil, Helena relaciona entre sí, de manera nueva y caprichosa, materiales de muy diverso tipo, reduce los restos de materia a su más concentrado extracto y arma con ellos un objeto capaz de condensar muchos aspectos distintos del universo.

Cuando Helena se refiere a su infancia, dice: «La infancia, joven, no tiene ninguna gracia pero tiene toda la gracia del mundo, y por cualquiera de las razones siempre volvemos a ella. Está todo ahí» (221). Así, la infancia admite atribuciones que, 
según un orden lógico, serían incompatibles: «no tiene ninguna gracia» al tiempo que «tiene toda la gracia del mundo». El periodista no comprende estas reflexiones: “¿A qué se refiere? ¿A la imaginación infantil?» (221) le dice, y al intentar traducir el enunciado de Helena en un concepto reconocible, lo vacía de su fuerza perturbadora para ubicarlo en el tránsito de los sentidos compartidos, esos que, de tan repetidos, ya dicen poco o casi nada. En cambio, lo que Helena rescata de la infancia es su capacidad de albergar lo opuesto, la nada y la totalidad al mismo tiempo, su talento para congregar lo inesperado. Estas son las razones por las que, siempre, volvemos a ella, como inspiración para crear, según las posibilidades que despliega la subjetividad infantil, pero también como invitación a percibir el mundo a su manera.

$\mathrm{El}$ «módulo» inventado por Helena Saort es un «icosaedro ahusado» compuesto de muchas caras, cada una de las cuales tiene una textura, un color, una densidad y una forma peculiares, «unas llevan diminutos apósitos, otras se abren, o ceden, o palpitan", "producen crujidos o tintineos, de vez en cuando acordes disonantes» (212). Por tanto, al tiempo que posibilita una experiencia donde la percepción y la sensibilidad recuperan todo su espesor, convoca a arriesgar sentidos capaces de expresar de qué trata cada lado de este singular poliedro, tan estimulante para la imaginación como resistente a ser capturado en interpretaciones unívocas. Por ejemplo, ante el sonido que produce una de sus caras, Helena expresa: «Este berridito puede ser de un hombre que se transformó en asno en un cuento de hadas, o puede ser el vidrio de la puerta del aula donde usted aprendió a sumar. Puede ser su alarido cuando nació, o el de su madre al verlo enchastrado de placenta» (238). De este modo, el «módulo», creado por una artista-niña, hace extensibles las posibilidades de la subjetividad infantil a sus usuarios, invita a renovar la existencia de la materia dotándola de nuevas significaciones, todas posibles, todas aptas de convivir simultáneamente. Así como la imaginación infantil transforma los objetos más comunes y triviales, lo despreciado o ignorado por la vida adulta, en otra cosa de cualidad muy diferente, así como los niños hacen de una piedra un ser humano, de dos palitos una casa, o convierten los papeles de estaño en tesoros de plata y los céntimos de cobre en escudos; así también el berridito del «módulo» puede ser ocasión para que proliferen un cuento maravilloso, un recuerdo ignorado, un origen a ritmo de llanto y alarido.

\section{Algo que no estaba ahí}

En el Prólogo a ;Realmente fantástico! y otros ensayos Cohen anuncia que en todas las piezas críticas que componen el libro "hay un plan de forma, casi siempre narrativa» (2003a:11-12). Si nos detenemos en el ensayo que da título al volumen podemos ver que la narración aparece allí en varios niveles que se superponen y se alternan. En primer lugar, observamos un relato principal que cuenta los derroteros de JD en su intento de escribir una historia, donde tienen lugar las diversas preguntas, decisiones, dilemas con los que este personaje se va encontrando al avanzar en su tarea. En segundo lugar, asistimos a la narración de JD al mismo tiempo en que se va construyendo, un relato desgajado en sus múltiples posibilidades y alternativas, todas expuestas a medida que son consideradas, 
escogidas, descartadas. Y, por último, la narración aparece en su dimensión autorreflexiva: una escritura que habla de sí misma, arriesga definiciones, deslinda rasgos de una poética, al tiempo que se crea. De este modo vemos que la figura de ensayista que construye Marcelo Cohen no puede escindirse de una figura de narrador: sus reflexiones se ven invadidas por las capacidades de la narración para mostrar aquello sobre lo que se quiere discurrir críticamente, $y$, al escoger un «plan de forma», sus ensayos se hacen narrativa. Además, también en su producción crítica-ensayística reaparece la imagen de la creación realizada a partir del desperdicio, conjugada con una figuración de la literatura como casa para habitar. En «Prosa de Estado y estados de la prosa», artículo publicado en el número 8 de la revista Otra Parte, concluye diciendo:

\footnotetext{
Décadas después de los experimentos terminales, el narrador atraviesa el boquete que abrieron los demoledores, pertrechado con los lenguajes que ellos llegaron a dominar y transformaron, cargado con escombros y con residuos útiles, y del estrecho corredor en donde se encuentra hace una casa, y la cuida, y se empeña en ampliarla. No capitula. No se acomoda. No se atrinchera. Pero no desdeña procrear... (2006a:8)
}

Una vez acontecida la experiencia de las vanguardias, el escritor también deviene trapero y hace de los escombros y residuos — saldo sobrante de la demoliciónmateria para construir, donde había solo ruinas, una casa que, tal como la vivienda de Justín y la zona de Dainez, recibe los cuidados y el esmero de su creador que se empeña en hacerla proliferar. Los materiales son restos en dispersión, elementos disímiles y apartados que deben conjugarse para crear lo nuevo. Tal como lo hace el niño descripto por Benjamin, el procedimiento privilegiado consiste en establecer relaciones entre lo aparentemente distante e irreconciliable, y su resultado es la unión y condensación de lo disperso. Como vimos anteriormente, este es el modo de creación de Justín, Dainez y Helena Saort. También JD, el escritor protagonista de "iRealmente fantástico!», está convencido de que si se ponen en relación contenidos muy diversos empezará a formarse una historia, «como una síntesis química entre sustancias combinables» (2003a:185). Y así sucede en su propia escritura, motivada a partir de la asociación entre dos elementos que le proporcionan los acontecimientos más nimios y fortuitos: la imagen de una muchacha opulenta y un viejo fornido mirando el discurrir de los coches en el puente que cruza la autopista, avizorada durante una parada que realiza el ómnibus que lo lleva de regreso a su ciudad, se combina con la anécdota que le cuenta un joven en la cola del correo sobre el romance de su padre recientemente viudo con una jovencita.

Finalmente también éste es el procedimiento privilegiado por Cohen para su escritura. Cuando en «Pequeñas batallas por la propiedad de la lengua» recupera su experiencia como exiliado en Espańa, recuerda que allí disponía ante todo de elementos variados, proliferación heteróclita donde convivían lo local y lo foráneo: «la libreta de almacenero y la computadora, el chorizo español y la medialuna, el hule grasoso y tajeado del asiento de un colectivo 60 y el camarote acolchado de un tren Talgo, el bombo legüero y el sámpler, el Mediterráneo y el río Luján» (2006b:48). Entonces, descubrió que, para poder escribir, debía generar la posibili- 
dad de que estos materiales establezcan relaciones: «tomar esos elementos aleatorios, al menos los más insistentes, ofrecerles un espacio y dejar que se relacionaran; que desarrollaran leyes propias, transitorias», y así, «en el tumulto de las relaciones se irían definiendo objetos nuevos» (49).

«Idear nexos entre dos o más motivos cualesquiera» (2003b:11), condensar restos de imágenes, percepciones y contenidos mentales de distinta procedencia; vincular fragmentos de lo diverso; el procedimiento aspira a la creación de «una forma». $\mathrm{El}$ anhelo de "una forma todavía desconocida» declarado por Cohen en "Unas palabras», prólogo de su antología de cuentos La solución parcial (2003b:11), y el reto de "obtener una forma de lo indefinido" que se propone JD en "iRealmente fantástico!» (2003a:192) motivan la obstinada búsqueda del escritor. Pero, según Cohen, una narración no es un artefacto armado con piezas de meccano con sus partes simétricamente ensambladas (2003a: 147). Por tanto esa forma está mucho más cercana al desorden, o a un orden que no puede sino ser inseguro y efímero, que a cualquier modo de acabado y perfección. Es en este sentido que la narración puede aprovechar el caos como elemento constructivo. ${ }^{3}$ Dice Cohen que la literatura se ocupa de incorporar el caos a la forma sin disfrazarlo de otra cosa (2003b:12). Esta idea, tomada de Beckett, reaparece en varios otros ensayos (véase 2003a:124, $142,146)$ y además es replicada por Dainez en «Un hombre amable», quien expresa: "Que haya para nosotros una forma. Una forma neutra, tolerante, una forma de contenga el caos sin disimularlo» (2004:203). Así, lo importante es admitir el caos de modo tal que su presencia sea ostensible, un caos que genere estructuras alejadas del equilibrio, capaces de albergar lo improcedente, lo aleatorio, lo intempestivo.

La protagonista de «Usos de las generaciones» también «Busca una forma. Un medio de unión, como un lenguaje, pero también una cosa que se pueda poner en el mundo, para ver y tocar» (2001:220). Así como los nińos, según Benjamin, construyen su propio mundo objetal, un mundo pequeño dentro del grande, del mismo modo opera el narrador y el artista en algunos ensayos y ficciones de Cohen. JD advierte que durante el proceso creativo la actividad de su mente ha recortado un mundo y el impulso fantástico no ha hecho más que "poner algo que no estaba ahí. Una impertinencia» (2003a:208). También Dainez, subido a la cumbre del zigurat donde se ha amontonado la basura, estampa «un mundo en lo que parecía una nada» (2004:146), convirtiendo pilas de restos informes en novedad.

Por momentos Dainez compara la zona con los números primos que debe idear para vender al consorcio en el cual trabaja: los teoremas, el número Pi o las pirámides adquieren las condiciones del fantasma, creaciones de la imaginación que se tornan creíbles por su apariencia coherente y autosuficiente. Dice Dainez: «Un hígado de pollo era tan real como el teorema de Fermat. O tan imaginario (...). Real e imaginario. Vieja dupla. Qué tedio. Qué tándem embustero. Un buen invento era tan milagroso como la existencia» (2004:289-290). En «Henry James fabrica un fantasma» Cohen insiste sobre esta cuestión: el fantasma, que pertenece al rango de las ficciones, solo necesita una estructura coherente, la prueba de un efecto y la aceptación de alguien para ańadirse al campo común de las existencias que respetamos y formar parte de aquello que experimentamos como realidad (2003a:18). Cohen toma de Wallace Stevens la idea de que el acto imaginativo amplía el campo de lo normal introduciendo algo en la realidad, algo singular, profuso en sus detalles (2003a:19). Cuando el fantasma aparece ahí, sumándose a nuestro mundo como algo que existe, logra estremecer la consistencia de las 
categorías del pensamiento y los límites que se postulaban infranqueables exhiben su vacilación. Por tanto, Cohen propone que no solo existe contigüidad entre la materia y la mente, sino también entre la experiencia y la invención (2003a:150, también en 2003a:137). En algunas de sus narraciones los lazos se desocultan, por ejemplo en «Un hombre amable» donde Dainez crea la zona aprovechando la continuidad entre su mente y el barrio: «el mundo y mi cerebro están hechos de lo mismo» (2004:259) expresa el protagonista, y emprende un acto de creación a partir de la posibilidad de que la realidad empírica y la mente intercambien sus papeles.

De este modo, en los ensayos y narraciones de Cohen se construye una concepción de la literatura como "creación de objetos de existencia incorpórea, habitantes de un espacio intermedio entre el pensamiento y la materia» (2003a:215). La narración es un «mundito» que se incorpora al mundo, algo que se pone ahí donde parecía no haber nada, un mundo pequeño que se instala dentro del grande y al hacerlo lo modifica de algún modo. Si con este accionar la imaginación amplifica, en esa capacidad radica la potencia de la literatura como forma de conocimiento. Esta disposición que Cohen atribuye a la literatura se vincula con la posibilidad de que dejemos de hablar del conocimiento como adecuación y empezamos a pensarlo como aumento de la capacidad de relación con las cosas (19). No se trata de alumbrar una verdad o develar el enigma que nos permitiría acceder a lo profundo, menos aún de adquirir algún tipo de explicación que nos deje conformes por un rato. Lo que permite la imaginación, ese acto impertinente, es el acontecer de la experiencia, pequeńos y mínimos instantes donde es posible establecer un lazo franco con el mundo.

En este sentido, el conocimiento que propicia la literatura se vincula con la posibilidad de generar una sensación que, tal como la flor de manzanilla que ha brotado en medio de una laja y sorprende a Dainez al punto de dejarlo boquiabierto, «no explica ninguna totalidad, no expresa, no colma ninguna esperanza. No crea reglas nuevas» (2004:297), pero sí produce un vahído dulce, caricia de la percepción. Cohen reconoce en sus ensayos que este tipo de sensaciones son poco comunes en un mundo donde las mediaciones estridentes y las diversas formas del simulacro proliferan al ritmo de la velocidad del capitalismo monopolista y global. Pero al mismo tiempo reconoce que el arte y la literatura harían posible el acontecer de algo del «orden de lo sensual, quizás de lo sexual» (2003b: 10). En el prólogo a $L a$ solución parcial, Cohen expresa que «un buen cuento es el que regala una sensación verdadera —o la devuelve— (2003b:11). Allí, en esa capacidad para recuperar el momento de una sensación, radicaría el contenido de verdad de la literatura: «una verdad de la sensación en sí que no admite matizaciones ni refutaciones» (2003a:186).

\section{Un despertar a la experiencia}

Cuando el periodista de "Usos de las generaciones» realiza con el «módulo» distintas maniobras tales como restregárselo contra el mentón, acariciar una arista con su pulgar derecho o lanzarlo al aire para observarlo mientras gira; el narrador se detiene a describir los modos en que, con cada operación, los rasgos del muchacho se distienden y trastornan. El joven «se contrae, como mareado de barco» y está "un poco atónito», "como si cada aspecto del módulo avivara en el cuerpo una 
huella distinta» (2001:212). Así, cuando el protagonista y también cada uno de los personajes del cuento se encuentran con el «módulo» no pueden disimular que algo del orden de la turbación les está sucediendo, algo que se inscribe en el rostro y altera el cuerpo, algo capaz de avivar las huellas más recónditas y suscitar lo insospechado: «una sensación mía que había olvidado o todavía me faltaba tener» (220). Porque, según expresión de su creadora: «jel módulo es cosa del arte!», «No digo que sea mejor, sino que da otro tipo de experiencia» (237).

El escritor de $;$ Realmente fantástico! intuye que, si consigue contar la historia que está persiguiendo, es probable que descubra algo nuevo y eso "será parte de un cambio» (2003a:185). En el instante en que sucede su práctica creativa emerge «un JD diferente del de un momento antes», y este evento tiene un carácter particularmente disruptivo respecto del acontecer ordinario: no solo se sustrae del orden temporal, constituyéndose como «un foco de eternidad anidado en la miríada de instantes», sino que también escapa al tiempo discursivo (190). Pero «lo bueno sería que la novedad afectara incluso al lector» (190), y este desplazamiento de la conmoción producida por el hecho estético desde el escritor al lector es algo que se repite en los ensayos de Cohen. ${ }^{4}$

Con la creación de la zona y cada una de sus apariciones, Dainez, protagonista de «Un hombre amable», se vuelve «más ágil, no nuevo pero al menos recreado» y, si antes había estado alicaído, aplastado por cierta tirantez, desde que sube al zigurat ha ganado «transparencia de ánimo» y «una discreta flexibilidad» (2004:149). Porque, cada vez que Dainez mira la zona, «se estremece de sensación verdadera» (173, énfasis nuestro).

Así vemos que en los ensayos y narraciones de Cohen son recurrentes las escenas donde la experiencia artística, la escritura o la práctica creativa así como también la lectura, el contacto con una pintura, performance u objeto artístico, el encuentro con la música ${ }^{5}$ o el cine, les hace algo a los sujetos, modifica de algún modo su acontecer en el mundo, inscribe un cambio en su subjetividad de forma tal que ya no pueden reconocerse tal como eran un momento antes, el instante previo al acontecimiento del arte. En muchos casos, el emerger de un sujeto diferente se lleva algo a cambio, porque, según Cohen «a ninguna sabiduría, como a ninguna ignorancia fecunda, se accede sin desprendimiento» (2003a:48). Quizás con esto pueda relacionarse la afasia que, hacia el final de la nouvelle, deja a Dainez emplazado en el más pleno silencio.

Las dos figuras construidas en cierta zona de la producción ensayística y ficcional de Marcelo Cohen -el trapero que crea a partir de los desperdicios que ha arrojado la sociedad capitalista y el narrador que se obstina en poner en palabras la experiencia - confluyen en una misma idea de comunidad. Si, como vimos anteriormente, la literatura consiste en crear un lugar, singular y autosuficiente, y, según Cohen, «un espacio hipotético se vuelve banal si no se ofrece como lugar de reunión, de comunidad, de ágape» (2006b:55); todos estos espacios — la zona de Dainez, la vivienda de Justín, las narraciones de Cohen - invitan a quedarse y pasar allí un buen rato. La casa de Justín no solo atrae a Dainez haciéndolo sentir «abrigado y monacal» (2004:196), sino también a otros sujetos foráneos, los expulsados del sistema, que son recibidos allí con hospitalidad. Así, el cementerio se va convirtiendo en un hospicio de extranjeros, reunidos alrededor del fuego donde Justín invita a compartir: "Arrímese, amigo. Yastamo» (275). Asimismo, según Cohen, el éxito o fracaso del escritor se parecen a los del buen anfitrión, él también ofrece un lugar para vivir una temporada y, quizás, volver más adelante (2003b:9). 
De este modo, se construye una figuración de la literatura como «espacio» y del narrador como aquel que "crea un lugar», «hace una casa» con restos de escombros, ruinas, basura, esquirlas de lo roto que se propagaban en dispersión. Ese espacio invita a los otros, extraños, y además asume las características de la otredad: admite rasgos distintos y contrapuestos a los que dominan en este lugar, sociedad masmediática, capitalismo monopólico y global, en el que coincidimos todos. $\mathrm{O}$ mejor aún, posibilita aquello que en el mundo está siendo relegado, a punto de perderse, al borde de su desaparición. Si el lenguaje «en vez de comunicar a la gente la separa» (2003b:10), los «munditos» creados por la literatura se postulan como «suculentas alternativas al mundo único en que, obligados a entendernos, nunca lo conseguimos» (2003a:189). Si estamos acostumbrados a un mundo lleno de mediaciones estridentes, reverberación de la farsa y del simulacro, la literatura, en cambio, es un lugar donde las sensaciones son más vivas, donde es posible «un despertar a la experiencia» (2003b:11).

Así, donde solo quedaban los residuos finales del progreso, ante el despojo, el aislamiento, el individualismo, la incomunicación, Cohen propone la «apertura intermitente de lugares hospitalarios» (2006b:51). Espacios que comunican allí donde acontece el relato y la mejor respuesta «no es una opinión, mucho menos una interpretación, sino otro relato» (2003a:83). Historias que se hilvanan y entretejen, disposición a la escucha atenta, gestos que cifran el sentido de la expresión compartir. Lugares de comunidad donde el prodigio de la sensación puede suceder, inminente, en cualquier instante. Así, esa casa, zona, literatura; esa otra parte, impertinente, profusa, caótica, nos pone del lado de la vida. ${ }^{6}$

\footnotetext{
Notas

${ }^{1}$ Todas las citas pertenecientes a textos de Marcelo Cohen que forman parte del corpus de análisis serán indicadas con el año de publicación de la edición consultada y el número de página correspondiente.

${ }^{2}$ Reconocemos los estudios de Miriam Chiani como un antecedente importante para pensar la vinculación de la figura del poeta como trapero propuesta por Benjamin con la literatura de Marcelo Cohen, y en particular con «Un hombre amable»; y además para pensar los modos en que la narración y la experiencia tal como son entendidas por Benjamin pueden relacionarse con la poética de Cohen (ver Chiani, 2001a:29-30, 2001b, 2010:112).

${ }^{3}$ Miriam Chiani ha indagado las posibilidades del caos como elemento constructivo en la narrativa de Marcelo Cohen, deteniéndose sobre todo en el análisis de El fin de lo mismo (ver Chiani, 1996).

${ }^{4}$ Por ejemplo en «En opaco mediodía» se propone escribir «para despabilarse de a poco, con mínimas sacudidas, y eventualmente despabilar a uno que otro» (2001b:56).

${ }^{5}$ Miriam Chiani ha estudiado la importante presencia de la música en la poética de Marcelo Cohen, proponiendo la posibilidad de explorar en la obra de este autor un "comparatismo productivo" que, en lugar de concentrarse en el mero registro de una fuente artística no verbal en una obra literaria, de cuenta también de «los efectos de las transformaciones
} 
que las cualidades estructurales de un sistema operan sobre otro, en este caso, las cualidades del arte musical sobre los procedimientos constructivos de las artes verbales» (2010:106-107, ver además su Tesis Doctoral: "Cuando el narrador escucha. Sobre la presencia de la música en los textos críticos y narrativos de Marcelo Cohen, 1973-2008», disponible en: http://www.memoria.fahce.unlp.edu.ar/tesis/te.764/te.764.pdf).

${ }^{6}$ Esta expresión pertenece a Marcelo Cohen, quien postula respecto de la literatura: «Sabemos que la literatura no es una herramienta; a lo sumo es una experiencia - la de hacerla - o un abuso que la imaginación hace de las flaquezas del recuerdo; un modo de estar, no forzosamente ejemplar ni útil y tampoco chispeante. Así nos pone del lado de la vida» (2001b:59, énfasis nuestro).

\section{Referencias bibliográficas}

Benjamin, W. (1986). El narrador. Consideraciones sobre la obra de Nicolai Leskov. En Sobre el programa de la filosofía futura y otros ensayos (pp. 189-211). Barcelona: Planeta-Agostini.

- (1993). Poesía y capitalismo. Iluminaciones II. Madrid: Taurus. (2002). Calle de mano única. Madrid: Editora Nacional. (2011). Denkbilder. Epifanias en viajes. Buenos Aires: El cuenco de plata.

Cohen, M. (2001a). Los acuáticos. Buenos Aires: Norma. (2001b). «En opaco mediodía». Milpalabras, (1), 49-62. (2003a). ;Realmente fantástico! y otros ensayos. Buenos Aires: Norma. (2003b). Unas palabras. En La solución parcial (pp. 9-12).

Madrid: Páginas de Espuma.

(2004). Hombres amables. Buenos Aires: Norma.

(2006a). Prosa de Estado y estados de la prosa. Otra Parte, (8), 1-8.

(2006b). Pequeñas batallas por la propiedad de la lengua. En Molloy, S. y Siskind, M. (Eds.), Poéticas de la distancia. Adentro y afuera de la literatura argentina (pp. 35-55). Buenos Aires: Norma.

Chiani, M. (1996). Escenas de la vida postindustrial. Sobre El fin de lo mismo de Marcelo Cohen. Orbis Tertius, I(1), 117-129.

(2001a). Represión, exilio, utopía y contrautopía. Sobre Marcelo Cohen. Orbis Tertius, 4(8), 21-32.

(2001b). La «fiesta seminal de las palabras». Sobre Marcelo Cohen. En Payeras Grau, M. y Fernández Ripoll, L., Actas del Congreso Internacional Fin(es) de Siglo y Modernismo (pp. 719-724). Palma: Universitat de les Illes Balears.

(2010). Cuando el narrador escucha. Sobre Marcelo Cohen. Arbor. Ciencia, Pensamiento y Cultura, CLXXXVI, 105-119.

\section{Sánchez, Silvina}

«Narrador, trapero, condensador de restos. Sobre la 
